\title{
Assessment of Some Characteristics and Properties of Zirconium Dioxide Nanoparticles Modified with 3-(Trimethoxysilyl) Propyl Methacrylate Silane Coupling Agent
}

\author{
Phi Hung Dao, ${ }^{1,2}$ Thuy Chinh Nguyen ${ }^{1},{ }^{1,2}$ Thi Lan Phung, ${ }^{3}$ Tien Dung Nguyen, ${ }^{3}$ \\ Anh Hiep Nguyen, ${ }^{2}$ Thi Ngoc Lan Vu, ${ }^{3}$ Quoc Trung Vu $\mathbb{D}^{3},{ }^{3}$ Dinh Hieu Vu, ${ }^{3}$ \\ Thi Kim Ngan Tran, ${ }^{4}$ and Hoang Thai ${ }^{1,2}$ \\ ${ }^{1}$ Graduate University of Science and Technology, Vietnam Academy of Science and Technology, 18 Hoang Quoc Viet, Cau Giay, \\ Hanoi 100000, Vietnam \\ ${ }^{2}$ Institute for Tropical Technology, Vietnam Academy of Science and Technology, 18 Hoang Quoc Viet, Cau Giay, \\ Hanoi 100000, Vietnam \\ ${ }^{3}$ Faculty of Chemistry, Hanoi National University of Education, No. 136 Xuan Thuy Road, Cau Giay District, \\ Hanoi 100000, Vietnam \\ ${ }^{4}$ NTT Institute of High Technology, Nguyen Tat Thanh University, 300A Nguyen Tat Thanh, District 4, \\ Ho Chi Minh 700000, Vietnam
}

Correspondence should be addressed to Thuy Chinh Nguyen; thuychinhhn@gmail.com and Hoang Thai; hoangth@itt.vast.vn Received 29 March 2021; Revised 4 June 2021; Accepted 15 June 2021; Published 22 June 2021

Academic Editor: Shahid Hussain

Copyright $\odot 2021$ Phi Hung Dao et al. This is an open access article distributed under the Creative Commons Attribution License, which permits unrestricted use, distribution, and reproduction in any medium, provided the original work is properly cited.

This study presents the results of surface modification of zirconium dioxide $\left(\mathrm{ZrO}_{2}\right)$ nanoparticles by 3-(trimethoxysilyl) propyl methacrylate silane coupling agent by assessing some characteristics and properties of modified $\mathrm{ZrO}_{2}$ nanoparticles by infrared spectroscopy, thermogravimetric analysis, size distribution, zeta potential, and field emission scanning electron microscopy methods. The modified and unmodified $\mathrm{ZrO}_{2}$ nanoparticles have been used as nanoadditives for organic coatings based on acrylic emulsion resin. The abrasion resistance of acrylic coating was evaluated according to ASTM E968-15. The obtained results show that $\mathrm{ZrO}_{2}$ nanoparticles were functionalized successfully with 3-(trimethoxysilyl) propyl methacrylate silane. The modified $\mathrm{ZrO}_{2}$ nanoparticles exhibit a positive effectiveness in the enhancement of the abrasion resistance of acrylic resin coating compared to unmodified $\mathrm{ZrO}_{2}$ nanoparticles.

\section{Introduction}

Zirconium dioxide $\left(\mathrm{ZrO}_{2}\right)$ or zirconia nanoparticles have been used in many technological fields such as catalysis, sensors, dielectric materials, polymeric nanocomposites, metallic nanocomposites, coating, semiconductor, or optical materials, thanks to their advantages including high strength, good natural color, high transparency and chemical stability, transformation toughness, thermal stability, chemical resistance, anticorrosion, and microbial resistance. There are several available methods for producing zirconia nanoparticles, consisting of hydrolysis, sol/gel, hydrothermal, pyrolysis, microwave plasma, or thermal treatment [1-4].

Recently, zirconia nanoparticles are interested as an enhancement additive for organic coating to improve the transparency, refractive index, hardness, elastic modulus, tensile strength, and thermal stability of polymer matrixes including poly (urethane-acrylate), poly (N-isopropylacrylamide), poly (methylmethacrylate), polyacrylamide hydrogels, or polypyrrole- (PPy-) derived polymer due to their great physical and chemical properties [5-11]. The properties of the $\mathrm{ZrO}_{2}$ nanocomposites depend on the size and content of zirconia nanoparticles in the polymer. 
There are few studies on surface modification of zirconia nanoparticles to increase the dispersion of zirconia nanoparticles in polymer matrices [12-14]. The $\mathrm{ZrO}_{2}$ nanoparticles modified with 3-methoxysilyl propyl amine significantly improved the mechanical properties of epoxy resin $[12,13]$. Yan et al. modified $\mathrm{ZrO}_{2}$ nanoparticles using $\mathrm{N}$-(2-aminoethyl)- $\boldsymbol{\gamma}$-aminopropylmethyl dimethoxy silane coupling agent and investigated the effect of nanometer $\mathrm{ZrO}_{2}$ content and silane coupling agent on the friction and wear properties of bismaleimide (BMI) nanocomposites [14]. The presence of $\mathrm{ZrO}_{2}$ nanoparticles contributed to the decrease in the frictional coefficient and the wear rate of the nanocomposites. The modified $\mathrm{ZrO}_{2}$ nanoparticles were dispersed in a polymer matrix better than untreated $\mathrm{ZrO}_{2}$ nanoparticles, leading to the better tribological performance of nanocomposites containing modified $\mathrm{ZrO}_{2}$ nanoparticles. $\mathrm{Xu}$ et al. ex situ synthesized functionalized $\mathrm{ZrO}_{2}$ nanoparticles from zirconium (IV) isopropoxide isopropanol complex in benzyl alcohol and 3-(trimethoxysilyl) propyl methacrylate and applied them in UV curable poly (urethane-acrylate) (PUA) coating [5]. The coating was completely transparent when using 20 wt.\% of $\mathrm{ZrO}_{2}$. The mechanical and thermal properties of PUA coating were improved significantly with the presence of functionalized $\mathrm{ZrO}_{2}$ nanoparticles. Sayllkan et al. modified the surface of $\mathrm{ZrO}_{2}$ nanoparticles with 2-acetoacetoxyethyl methacrylate for optical purposes [3]. The modified $\mathrm{ZrO}_{2}$ nanoparticles have a size of $6.22 \mathrm{~nm}$ (transmission electron microscope) and $14.7 \mathrm{~nm}$ (particle size analysis). The surface modification also increases the stabilization of $\mathrm{ZrO}_{2}$ nanoparticles [15].

Emulsion acrylic resin is widely used in daily life and industry because it has valuable properties such as high UV resistance, high aesthetics, weather resistance, and working well for various materials. In addition, it is environmentally friendly, low cost, and thus widely used in water-based paints and coatings for interior applications [16-19]. The evaluation of the effect of modified $\mathrm{ZrO}_{2}$ nanoparticles on the abrasion resistance of emulsion acrylic resin can contribute to developing the paint system based on acrylic and nanoadditives in life sciences and technologies.

It can be recognized that the surface modification of $\mathrm{ZrO}_{2}$ nanoparticles is necessary to improve their dispersibility in a polymer matrix. However, there are few reports related to the assessment of the efficiency with grafting of silane coupling agent on the surface of $\mathrm{ZrO}_{2}$ nanoparticles [20]. The purpose of this work is to evaluate some characteristics, properties including grafting efficiency, functional groups, thermal stability, size distribution, and water stability of $\mathrm{ZrO}_{2}$ nanoparticles modified with 3-(trimethoxysilyl) propyl methacrylate silane. Moreover, the effect of silane content as well as modified $\mathrm{ZrO}_{2}$ nanoparticle content on abrasion resistance of emulsion acrylic coating has been also tested and discussed.

\section{Experimental}

2.1. Materials. $\mathrm{ZrO}_{2}$ nanoparticles (99\%) and 3-(trimethoxysilyl) propyl methacrylate silane (MSPMS) were provided by Sigma Aldrich, USA. Emulsion acrylic resin
(Plextol R 4152, solid content of $49 \pm 1 \%, \mathrm{pH}=7.0-8.5$, density of $1.05 \mathrm{~g} / \mathrm{mL}$ at $25^{\circ} \mathrm{C}$ ) was purchased from Synthomer Company. Texanol ester alcohol (2,2,4-trimethyl1,3-pentanediol, monoisobutyrate, $99 \%$, density of $0.95 \mathrm{~g} /$ $\mathrm{mL}$ at $25^{\circ} \mathrm{C}$ ), as a film-forming additive, was purchased from Dow Company. Others (ethanol 99.7\%, ammonia 25\%, and paint additives) are analysis chemicals.

2.2. Modification of $\mathrm{ZrO}_{2}$ Nanoparticles. The procedure for modification of $\mathrm{ZrO}_{2}$ nanoparticles by MSPMS was carried out based on different reports $[11,12,21,22]$ as follows: first, MSPMS was hydrolyzed in $100 \mathrm{~mL}$ of ethanol solution for 30 minutes at $50^{\circ} \mathrm{C}$. Next, $5 \mathrm{~g}$ of $\mathrm{ZrO}_{2}$ nanoparticles was added into above solution and magnetic stirred continuously for 2 hours at $50^{\circ} \mathrm{C}$. The solution was then homogenized on a T25 Ultra-Turrax digital high-speed homogenizer (IKA, Germany) for 30 minutes at a speed of $15,000 \mathrm{rpm}$. After that, the solid part was obtained by centrifuging and washing with ethanol 3-4 times before drying in a vacuum oven at $70^{\circ} \mathrm{C}$ to obtain modified $\mathrm{ZrO}_{2}$ nanoparticles (abbreviated by $\mathrm{m}-\mathrm{ZrO}_{2}$ ). The weight ratio of silane and $\mathrm{ZrO}_{2}$ nanoparticles and designation of the samples are presented in Table 1.

2.3. Characterization. The functional groups of unmodified and modified $\mathrm{ZrO}_{2}$ nanoparticles were analyzed by infrared (IR) spectroscopy, which means by a Nicolet iS10 (Thermo Scientific, USA) in $400-4000 \mathrm{~cm}^{-1}$ wavenumbers, $8 \mathrm{~cm}^{-1}$ resolutions, and 32 scans. The thermogravimetric (TG) analysis of the unmodified and modified $\mathrm{ZrO}_{2}$ nanoparticles was carried out using a DTG $60 \mathrm{H}$ (Shimadzu, Japan) at a heating speed of $10^{\circ} \mathrm{C} / \mathrm{min}$ in air from room temperature to $800^{\circ} \mathrm{C}$. Field emission scanning electron microscopy (FESEM) images of unmodified and modified $\mathrm{ZrO}_{2}$ nanoparticles were taken using S4800 FESEM (Hitachi, Japan). The dynamic light scattering (DLS, Zetasizer SZ-100, Horiba, Japan) was used to determine the size distribution and zeta potential of unmodified and modified $\mathrm{ZrO}_{2}$ nanoparticles. The samples were dispersed in distilled water, and DLS spectra were recorded at $25^{\circ} \mathrm{C}$.

2.4. Preparation of Acrylic Resin Coatings Containing Unmodified and Modified $\mathrm{ZrO}_{2}$ Nanoparticles and Evaluation of Their Abrasion Resistance. The acrylic resin coatings were prepared according to the following steps: first, the unmodified or modified $\mathrm{ZrO}_{2}$ nanoparticles were dispersed in distilled water by a TPC-15H ultrasonic tank for 30 minutes at room temperature with the nanoparticles/water ratio of $1 /$ $10 \mathrm{w} / \mathrm{v}$ (mixture A). Next, Texanol and other paint additives were added into acrylic resin at the additives/resin ratio of $1.5 / 100(\mathrm{w} / \mathrm{w})$ on an IKA RW16 stirrer with a speed of $400 \mathrm{rpm}$ for 15 minutes at room temperature (mixture B). The mixture A was mixed with mixture B on an IKA RW16 stirrer with a speed of $600 \mathrm{rpm}$ for 15 minutes at room temperature before ultrasonicating in the Branson sonifier 450 device for 5 minutes. The coating samples were made by the Erichsen film applicator thickness wiper (model 360) at wet film thickness of $120 \mu \mathrm{m}$ on glass. 
The abrasion resistance test of the coating samples has been performed using the falling sand abrasion method according to ASTM D968-15. The ElektroPhysik MiniTest 600 machine was used to measure the thickness of coatings. The volume of abrasive sand per unit coating thickness was the abrasion resistance of coating, expressed in L/mil (1 $\mathrm{mil}=25 \mu \mathrm{m})$ as

$$
\text { Abrasion resistance }\left(\frac{L}{\mathrm{mil}}\right)=\frac{V}{d},
$$

where $V$ is the volume of sand $(L)$, and $d$ is the coating thickness (mil).

The dispersion of $\mathrm{ZrO}_{2}$ nanoparticles in the acrylic resin matrix was evaluated by the field emission scanning electron microscopy (FESEM) method on a S4800 FESEM (Hitachi, Japan).

\section{Results and Discussion}

3.1. TG Analysis and Grafting Efficiency of Silane on $\mathrm{ZrO}_{2}$ Nanoparticles. Figures 1 and 2 show the TG and DTG diagrams of unmodified and modified $\mathrm{ZrO}_{2}$ nanoparticles. The weight loss of unmodified $\mathrm{ZrO}_{2}$ is zero, confirming that there is no presence of hydroxyl groups on the surface or inside the structure of $\mathrm{ZrO}_{2}$ nanoparticles [23]. From the TG diagrams, it can be seen that the modified $\mathrm{ZrO}_{2}\left(\mathrm{~m}-\mathrm{ZrO}_{2}\right)$ nanoparticles lost the weight in the range temperature of $200^{\circ} \mathrm{C}-500^{\circ} \mathrm{C}$. There is a broad peak on the DTG diagrams of $\mathrm{m}-\mathrm{ZrO}_{2}$ samples corresponding to the degradation of organosilane grafted on the surface of $\mathrm{ZrO}_{2}$ nanoparticles [21]. As varying the MSPMS content, the maximum degradation temperatures of $\mathrm{m}-\mathrm{ZrO}_{2}$ samples were changed (Table 2); however, the onset degradation temperatures of all $\mathrm{m}-\mathrm{ZrO}_{2}$ samples are similar.

The grafting efficiency of MSPMS to $\mathrm{ZrO}_{2}$ nanoparticles was estimated by the TG method $[20,21]$ and is given in Table 2. Because the surface of $\mathrm{ZrO}_{2}$ nanoparticles is hydrophobic, the grafting efficiency of MSPMS to $\mathrm{ZrO}_{2}$ nanoparticles is low, lowest value of $3.4 \%$ for $\mathrm{m}-\mathrm{ZrO}_{2}-15$ and highest value of $13.0 \%$ for $\mathrm{m}-\mathrm{ZrO}_{2}-3$. As increasing the silane content, the grafting efficiency of MSPMS to $\mathrm{ZrO}_{2}$ nanoparticles was decreased. This exhibits that the organosilane was residue in the modification process. In the investigated MSPMS contents, $3 \%$ of MSPMS is the most suitable for modifying $\mathrm{ZrO}_{2}$ nanoparticles with a high effectiveness.

3.2. IR Spectra of Unmodified and Modified $\mathrm{ZrO}_{2}$ Nanoparticles. The IR spectra of unmodified and $\mathrm{m}-\mathrm{ZrO}_{2}$ nanoparticles are shown in Figure 3. A strong band can be seen with the peaks at $570 \mathrm{~cm}^{-1}$ and $670 \mathrm{~cm}^{-1}$ characterized for $\mathrm{Zr}-\mathrm{O}-\mathrm{Zr}$ stretching vibration of $\mathrm{ZrO}_{2}$ nanocrystals $[13,24-26]$. There is no new peaks appeared in IR spectra of $\mathrm{m}-\mathrm{ZrO}_{2}$ nanoparticles, suggesting that the surface modification does not have any influence on the vibration of $\mathrm{ZrO}_{2}$ nanocrystals. It is difficult to observe the vibration of functional groups in MSPMS on $\mathrm{m}-\mathrm{ZrO}_{2}$ nanoparticles. This may be due to the high hydrophobic surface of $\mathrm{ZrO}_{2}$ leading to difficult formation of bonding between organosilane and $\mathrm{ZrO}_{2}$ nanoparticles. Moreover, the content of silane grafted on the surface of $\mathrm{ZrO}_{2}$ nanoparticles is quite small causing an effect on the appearance of organic groups in MSPMS on IR spectra of $\mathrm{m}-\mathrm{ZrO}_{2}$ nanoparticles. Therefore, only a small peak at $1120 \mathrm{~cm}^{-1}$ which is assigned to the stretching vibration of $\mathrm{Si}-\mathrm{O}-\mathrm{Zr}$ in the IR spectrum of $\mathrm{m}-\mathrm{ZrO}_{2}-5$ nanoparticles $[12,13]$ can be seen, as shown in Figure 4.

3.3. Morphology of Unmodified and Modified $\mathrm{ZrO}_{2}$ Nanoparticles. As observation from the FESEM images of unmodified and $\mathrm{m}-\mathrm{ZrO}_{2}$ nanoparticles in Figure 5, the $\mathrm{ZrO}_{2}$ nanoparticles are in spherical shape and have size in range from $50 \mathrm{~nm}$ to $150 \mathrm{~nm}$. The tendency to agglomerate $\mathrm{ZrO}_{2}$ nanoparticles can be observed due to the affinity of nanoparticles. The modification process has a negligible effect on morphology of $\mathrm{ZrO}_{2}$ nanoparticles.

3.4. Size Distribution and Zeta Potential of Unmodified and Modified $\mathrm{ZrO}_{2}$ Nanoparticles. The size distribution of unmodified and $\mathrm{m}-\mathrm{ZrO}_{2}$ nanoparticles is shown in Figure 6. The average particle size of $\mathrm{u}-\mathrm{ZrO}_{2}, \mathrm{~m}-\mathrm{ZrO}_{2}-3, \mathrm{~m}-\mathrm{ZrO}_{2}-5$, $\mathrm{m}-\mathrm{ZrO}_{2}-7, \mathrm{~m}-\mathrm{ZrO}_{2}-10$, and $\mathrm{m}-\mathrm{ZrO}_{2}-15$ nanoparticles is $287.1 \pm 77.5, \quad 283.6 \pm 59.0, \quad 414.6 \pm 99.1, \quad 269.7 \pm 24.6$, $457.6 \pm 37.7$, and $422.0 \pm 35.7 \mathrm{~nm}$, respectively. The size distribution of $\mathrm{m}-\mathrm{ZrO}_{2}$ nanoparticles at different contents of MSPMS is not systematic. This may be due to agglomeration of $\mathrm{m}-\mathrm{ZrO}_{2}$ nanoparticles occurred when using the high content of MSPMS. Moreover, the modification process of $\mathrm{ZrO}_{2}$ nanoparticles with MSPMS also increases the hydrophobic of nanoparticles [22, 27], leading to a difficult dispersion of $\mathrm{m}-\mathrm{ZrO}_{2}$ nanoparticles in water. The polydispersity index (PI) of all tested samples is higher than 0.3, corresponding to a broad size distribution of nanoparticles as reported by Danaei et al. [28]. The difference between particle sizes obtained in the FESEM method and DLS method is caused by the different dispersions of unmodified and $\mathrm{m}-\mathrm{ZrO}_{2}$ nanoparticles. For FESEM analysis, the nanoparticles were in solid and taken FESEM images, while for DLS analysis, the $\mathrm{ZrO}_{2}$ nanoparticles were dispersed in distilled water before taking size distribution. The nature of $\mathrm{ZrO}_{2}$ nanoparticles is hydrophobic; thus, they were dispersed difficultly in water, leading to the bigger size of the $\mathrm{ZrO}_{2}$ nanoparticles.

The zeta potential of unmodified $\mathrm{ZrO}_{2}\left(\mathrm{u}-\mathrm{ZrO}_{2}\right)$ nanoparticles and $\mathrm{m}-\mathrm{ZrO}_{2}-3$ nanoparticles shown in Figure 7 demonstrates the $\mathrm{u}-\mathrm{ZrO}_{2}$ nanoparticles have a positive charge surface $(21.4 \mathrm{mV})$ while $\mathrm{m}-\mathrm{ZrO}_{2}-3$ nanoparticles have a negative charge surface $(-12 \mathrm{mV})$. The modification process that caused the change in the charge on the surface of $\mathrm{ZrO}_{2}$ nanoparticles from the positive region to the negative region may be due to the conjugation effect of $\mathrm{C}=\mathrm{C}$ $\mathrm{C}=\mathrm{O}$ bond in MSPMS grafted onto the surface of $\mathrm{ZrO}_{2}$ nanoparticles to form the negative charge on oxygen atom. From the above results, it can be recognized that the $\mathrm{ZrO}_{2}$ nanoparticles were modified successfully with MSPMS. 
TABLE 1: Composition and designation of modified $\mathrm{ZrO}_{2}$ nanoparticles.

\begin{tabular}{|c|c|c|c|c|}
\hline \multirow{2}{*}{ No. } & \multirow{2}{*}{ Composition } & \multirow{2}{*}{ Designation } & \multicolumn{2}{|c|}{ Weight } \\
\hline & & & $\mathrm{m}_{\mathrm{ZrO}_{2}}(\mathrm{~g})$ & $\mathrm{m}_{\text {silan }}(\mathrm{mg})$ \\
\hline 1 & $\mathrm{ZrO}_{2}$ & $\mathrm{u}-\mathrm{ZrO}_{2}$ & 5 & 0 \\
\hline 2 & $\mathrm{ZrO}_{2}+3$ wt. $\%$ MSPMS & $\mathrm{m}-\mathrm{ZrO}_{2}-3$ & 5 & 15 \\
\hline 3 & $\mathrm{ZrO}_{2}+5$ wt. $\%$ MSPMS & $\mathrm{m}-\mathrm{ZrO}_{2}-5$ & 5 & 25 \\
\hline 4 & $\mathrm{ZrO}_{2}+7$ wt. $\%$ MSPMS & $\mathrm{m}-\mathrm{ZrO}_{2}-7$ & 5 & 35 \\
\hline 5 & $\mathrm{ZrO}_{2}+10$ wt. $\%$ MSPMS & $\mathrm{m}-\mathrm{ZrO}_{2}-10$ & 5 & 50 \\
\hline 6 & $\mathrm{ZrO}_{2}+15$ wt. $\%$ MSPMS & $\mathrm{m}-\mathrm{ZrO}_{2}-15$ & 5 & 75 \\
\hline
\end{tabular}

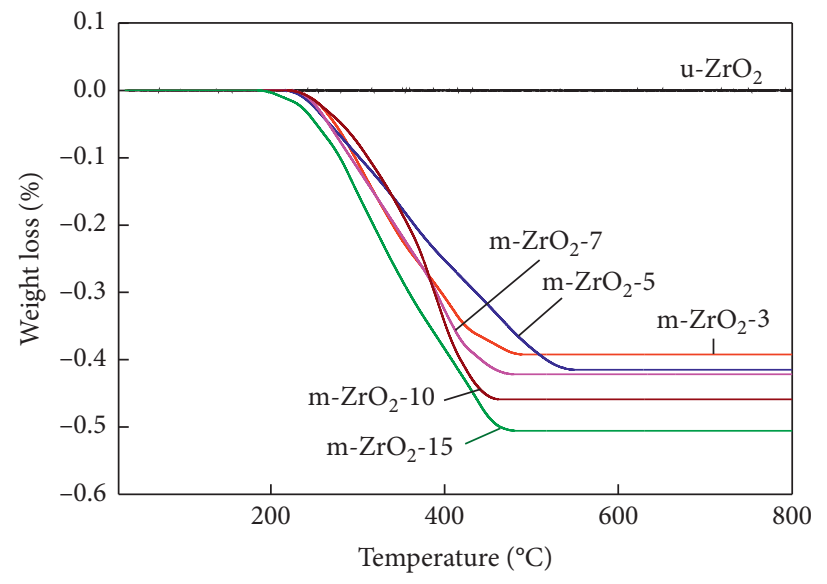

FIGURE 1: TG diagrams of unmodified and modified $\mathrm{ZrO}_{2}$ nanoparticles.

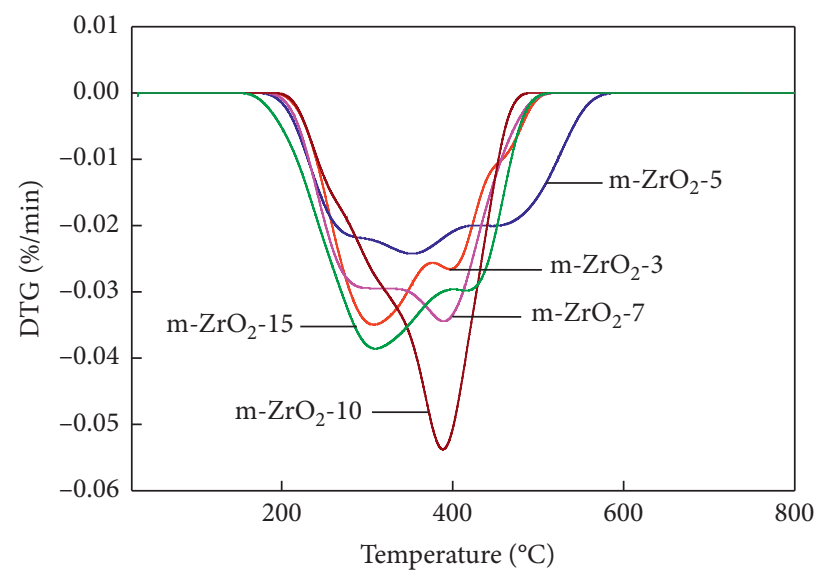

FIGURE 2: DTG diagrams of modified $\mathrm{ZrO}_{2}$ nanoparticles.

TABLe 2: Maximum degradation temperature and grafting efficiency of MSPMS to $\mathrm{ZrO}_{2}$ nanoparticles.

\begin{tabular}{lccccc}
\hline Sample & $\begin{array}{c}\text { Weight of MSPMS in } \\
\text { the sample (\%) }\end{array}$ & $\begin{array}{c}\text { Maximum degradation } \\
\text { temperature }\left({ }^{\circ} \mathrm{C}\right)\end{array}$ & $\begin{array}{c}\text { Weight loss } \\
(\%) \text { at } 500^{\circ} \mathrm{C}\end{array}$ & $\begin{array}{c}\text { Grafting } \\
\text { efficiency }(\%)\end{array}$ \\
\hline $\mathrm{u}-\mathrm{ZrO}_{2}$ & 0 & 0 & 0 & 0 & 0 \\
$\mathrm{~m}-\mathrm{ZrO}_{2}-3$ & 3 & 307.11 & 0.39 & 0.39 & 13.0 \\
$\mathrm{~m}-\mathrm{ZrO}_{2}-5$ & 5 & 354.30 & 0.42 & 0.42 & 8.4 \\
$\mathrm{~m}-\mathrm{ZrO}_{2}-7$ & 7 & 390.13 & 0.42 & 0.42 & 0.46 \\
$\mathrm{~m}-\mathrm{ZrO}_{2}-10$ & 10 & 388.61 & 0.46 & 0.51 \\
$\mathrm{~m}-\mathrm{ZrO}_{2}-15$ & 15 & 309.90 & 0.51 & 0.51 & 3.4 \\
\hline
\end{tabular}




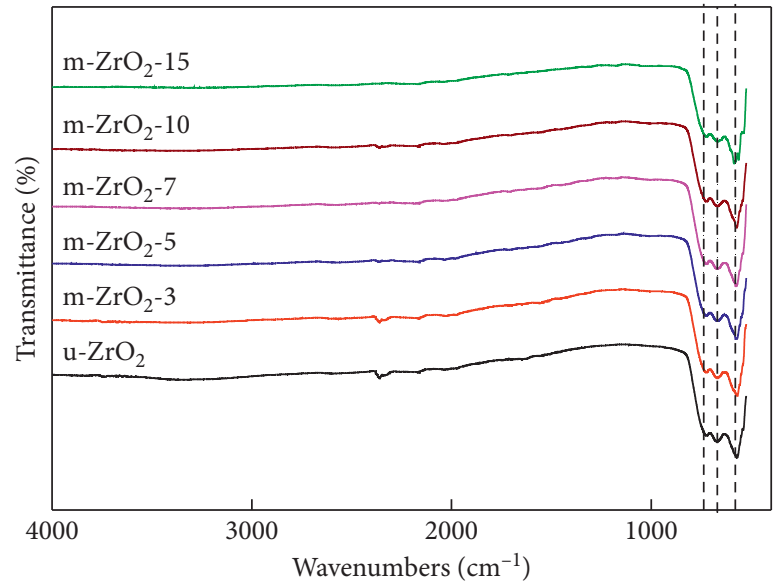

FIGURE 3: IR spectra of unmodified and modified $\mathrm{ZrO}_{2}$ nanoparticles.

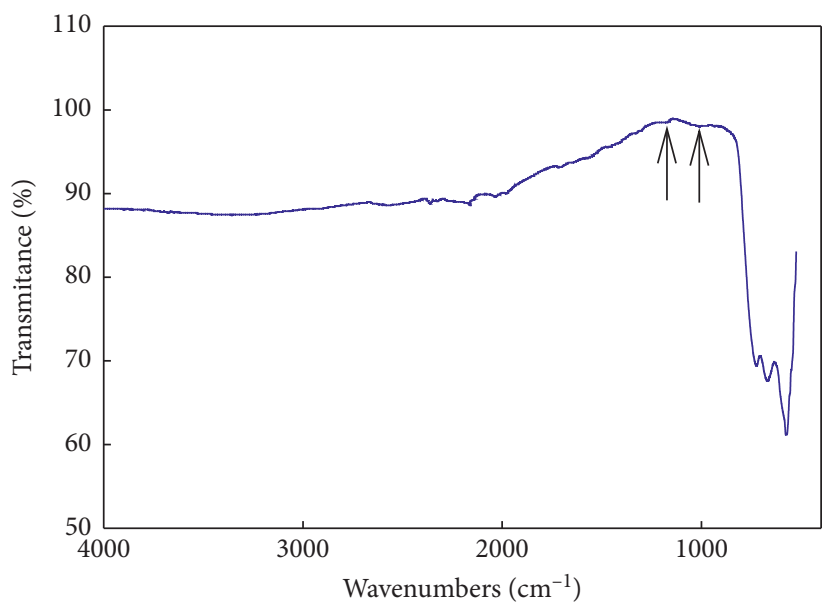

Figure 4: IR spectrum of $\mathrm{m}-\mathrm{ZrO}_{2}-5$ nanoparticles.

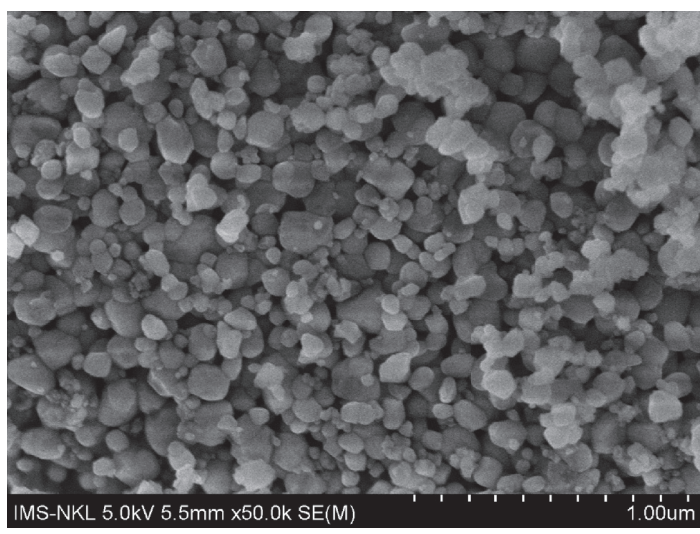

(a)

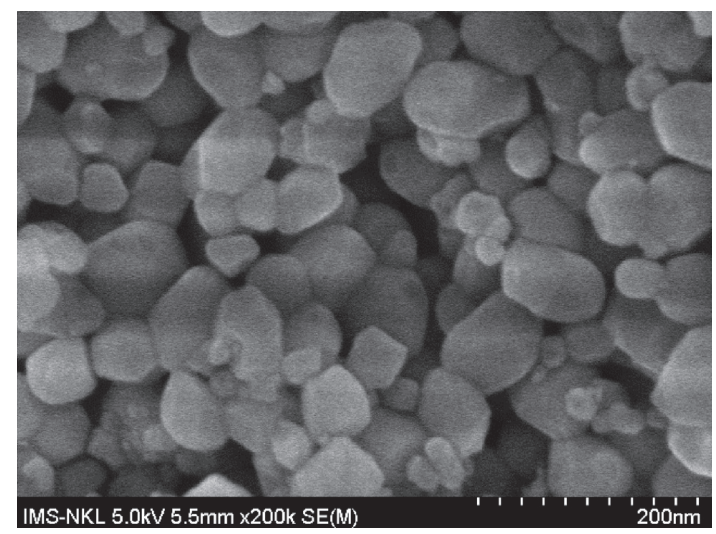

(b)

Figure 5: Continued. 


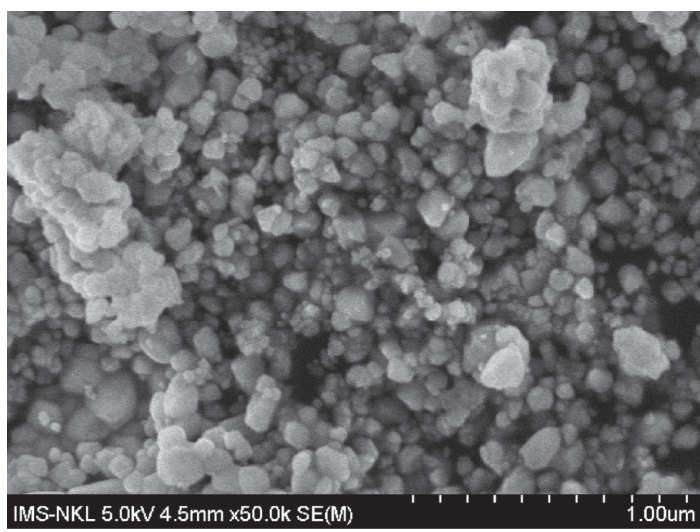

(c)

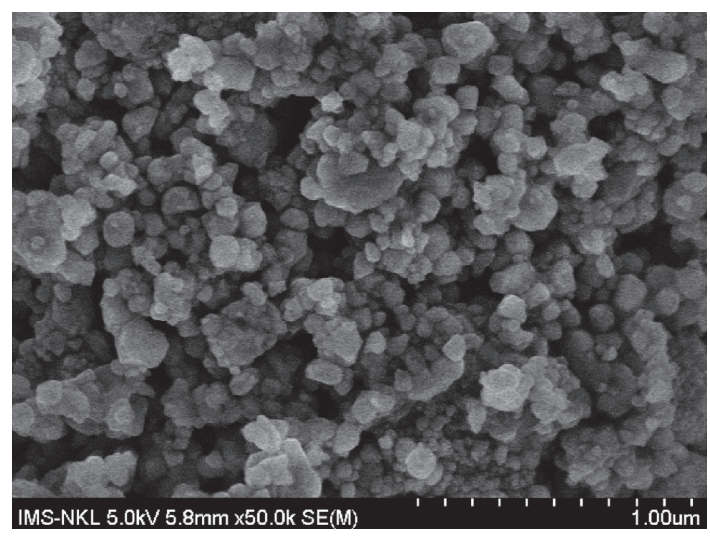

(e)

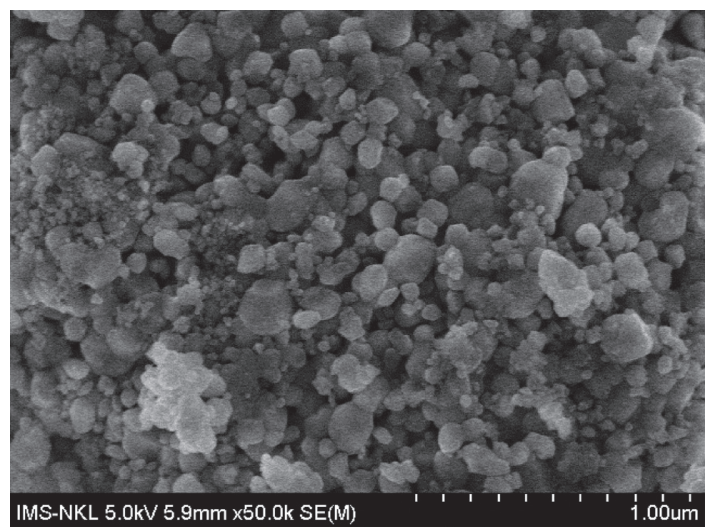

(g)

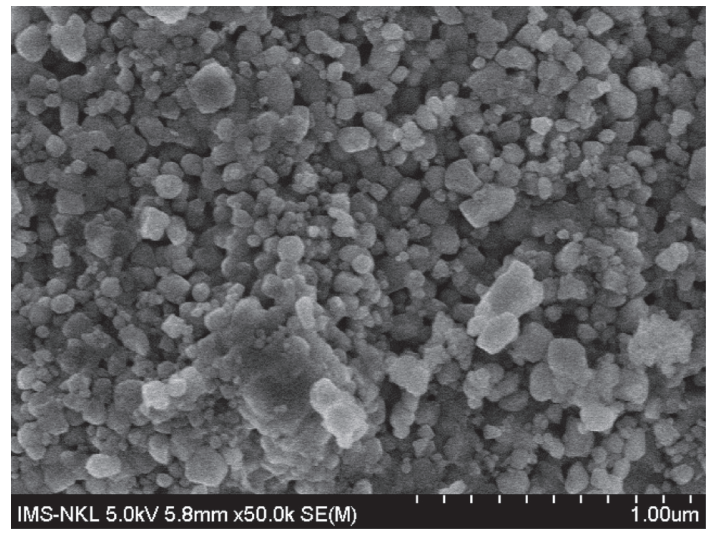

(i)

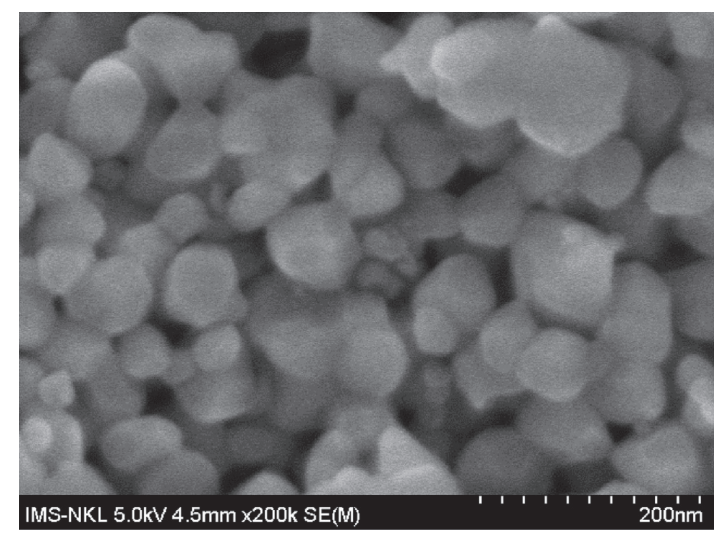

(d)

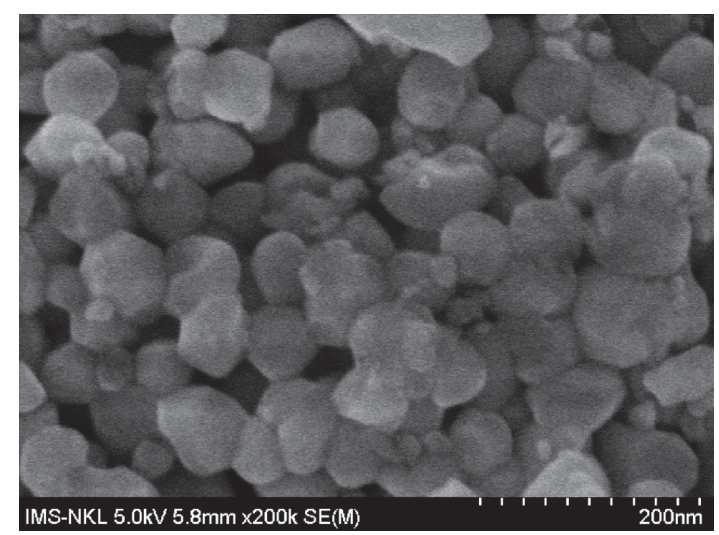

(f)

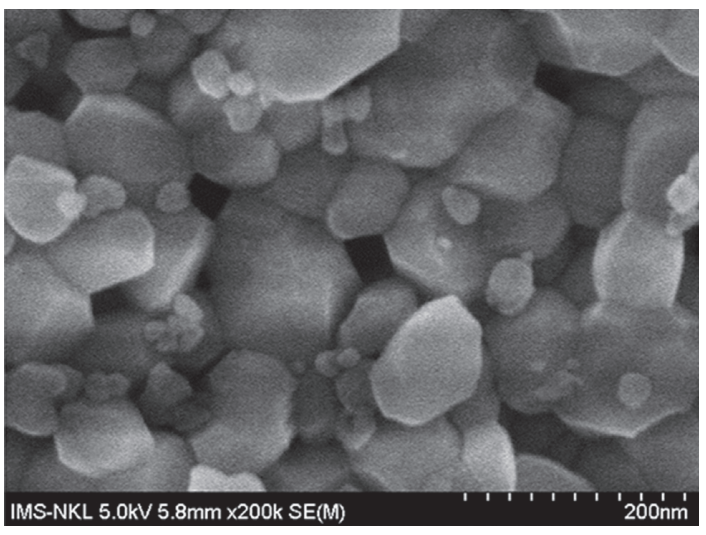

(h)

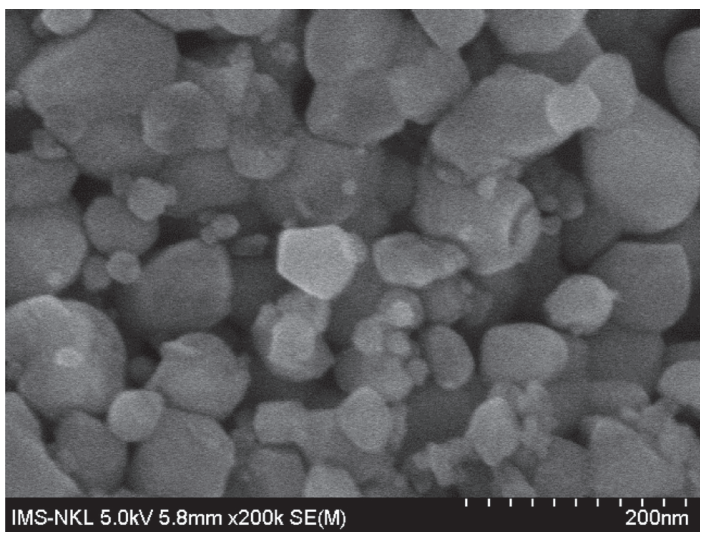

(j)

Figure 5: Continued. 


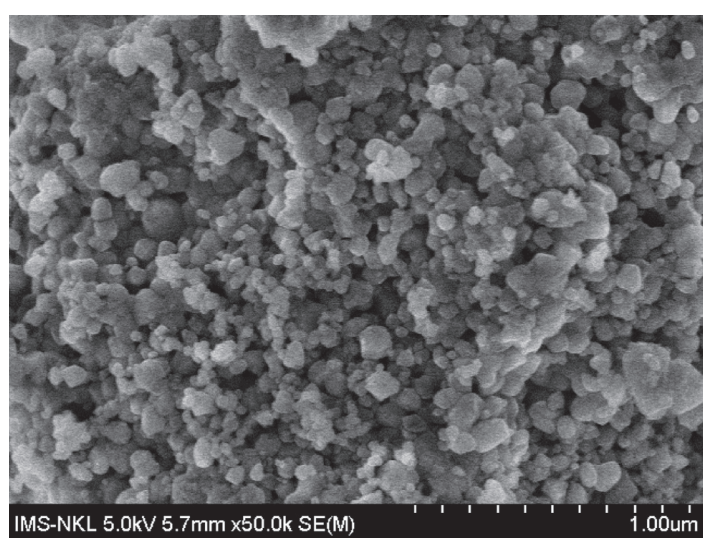

$(\mathrm{k})$

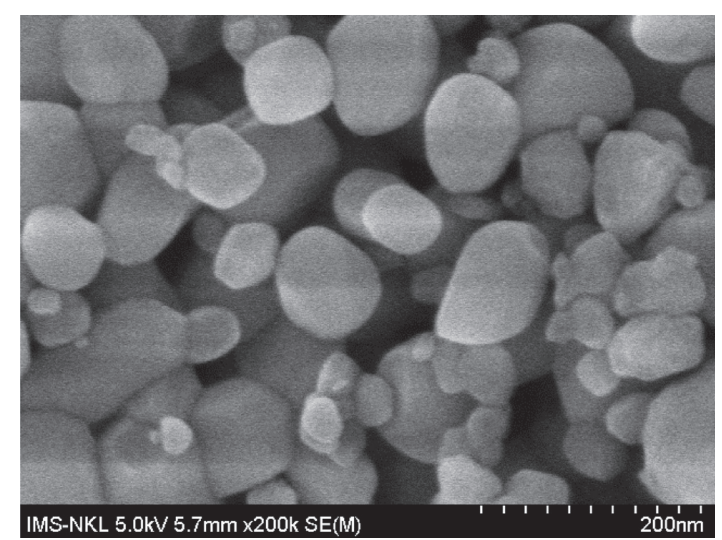

(1)

FiguRE 5: FESEM images of unmodified and modified $\mathrm{ZrO}_{2}$ nanoparticles at magnification of 50,000 times and 200,000 times. u- $\mathrm{ZrO} 2(\mathrm{a}, \mathrm{b})$, $\mathrm{m}-\mathrm{ZrO}_{2}-3$ (c, d), m- $\mathrm{ZrO}_{2}-5$ (e, f), m-ZrO $\mathrm{Zr}_{2}-7$ (g, h), m- $\mathrm{ZrO}_{2}-10$ (i, j), and m- $\mathrm{ZrO}_{2}-15$ (k, l).

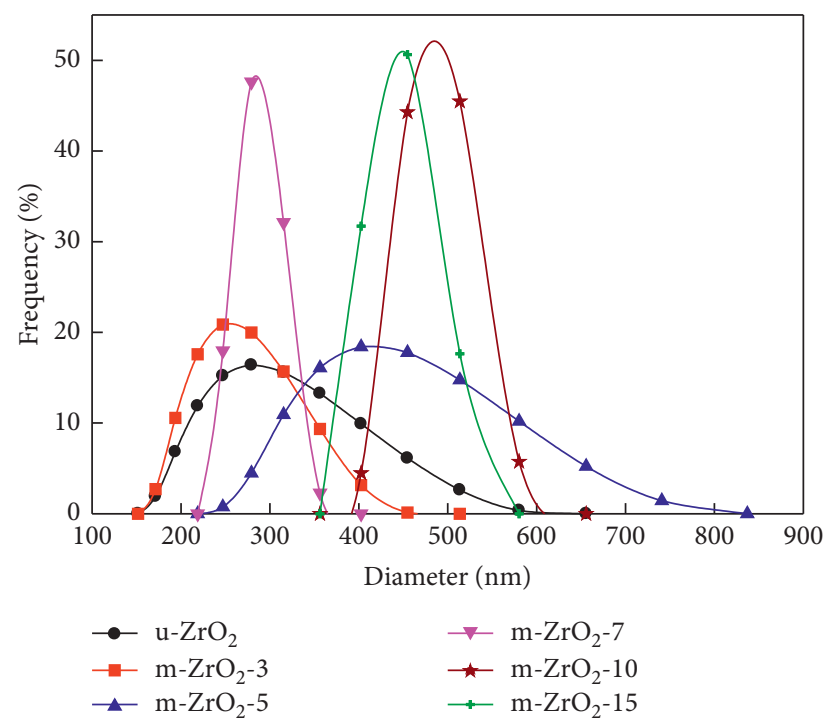

FIgURE 6: Size distribution of unmodified and modified $\mathrm{ZrO}_{2}$ nanoparticles.

These zeta potential values also suggest that unmodified and modified $\mathrm{ZrO}_{2}$ nanoparticles are relative stable in water.

\subsection{Application of Unmodified and Modified $\mathrm{ZrO}_{2}$ Nanoparticles for Emulsion Acrylic Resin Coating}

3.5.1. Abrasion Resistance. The effect of MSPMS content on the abrasion resistance of acrylic based coating containing 2 wt.\% of nanoparticles was evaluated and is given in Table 3. The acrylic resin and acrylic/u- $\mathrm{ZrO}_{2}$ coating has a low abrasion resistance, $83.60 \pm 4.47 \mathrm{~L} / \mathrm{mil}$ and $77.50 \pm 4.08 \mathrm{~L} / \mathrm{mil}$, respectively. In this case, $\mathrm{u}-\mathrm{ZrO}_{2}$ nanoparticles are not able to improve the abrasion resistance of acrylic coating due to the less dispersion of $\mathrm{u}-\mathrm{ZrO}_{2}$ nanoparticles in acrylic matrix, leading to the agglomeration of $\mathrm{ZrO}_{2}$ nanoparticles and the formation of defect in structure of coating, causing the decrease in the abrasion resistance of acrylic coating.
Using $\mathrm{m}-\mathrm{ZrO}_{2}$ nanoparticles makes a remarkable enhancement in abrasion resistance of coating containing because $\mathrm{m}-\mathrm{ZrO}_{2}$ nanoparticles dispersed more regularly in acrylic matrix. The best improvement in abrasion resistance of coating was observed for acrylic/m- $\mathrm{ZrO}_{2}-3$ coating, an increase of $62.33 \%$ as compared to acrylic resin coating.

To assess the influence of $\mathrm{m}-\mathrm{ZrO}_{2}$ nanoparticle content on the abrasion resistance of acrylic coating, the coatings based on acrylic resin and different contents of $\mathrm{m}-\mathrm{ZrO}_{2}-3$ nanoparticles were prepared. It can be seen that the abrasion resistance of coating containing $\mathrm{m}-\mathrm{ZrO}_{2}-3$ nanoparticles was increased as increasing the content of $\mathrm{m}-\mathrm{ZrO}_{2}-3$ from 0.5 to 2 wt. $\%$ and then decreased at the 5 wt.\% of $\mathrm{m}-\mathrm{ZrO}_{2}-3$ nanoparticles. This reduction can be caused by the agglomeration of $\mathrm{m}-\mathrm{ZrO}_{2}-3$ nanoparticles when using at high content. From obtained results, the suitable content of MSPMS silane for modification is $3 \mathrm{wt} \%$ and of $\mathrm{m}-\mathrm{ZrO}_{2}-3$ nanoparticles in acrylic resin coating is $2 \mathrm{wt} \%$ (Table 4 ). 


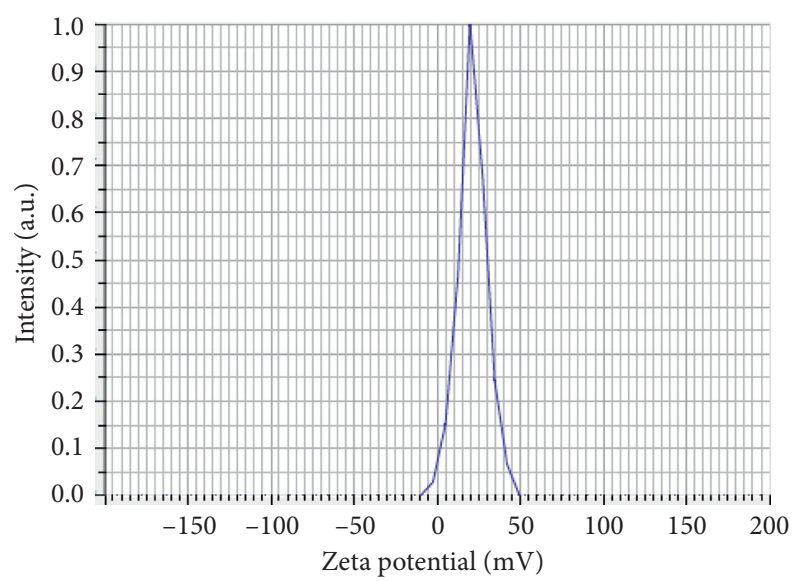

(a)

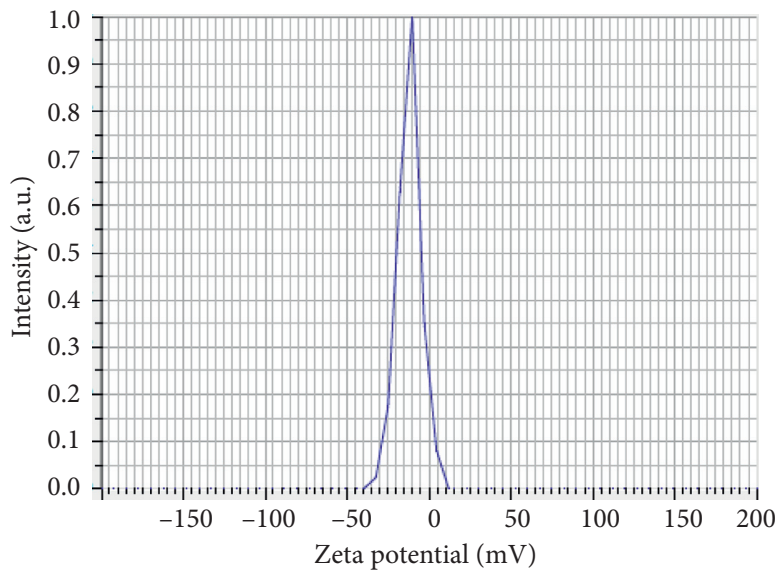

(b)

Figure 7: Zeta potential of $\mathrm{u}-\mathrm{ZrO}_{2}$ (a) and $\mathrm{m}-\mathrm{ZrO}_{2}-3$ (b) nanoparticles.

TABLE 3: Abrasion resistance of coating based on acrylic resin and 2 wt. $\% \mathrm{ZrO}_{2}$ nanoparticles.

\begin{tabular}{lr}
\hline Coating & Abrasion resistance (L/mil) \\
\hline Acrylic resin & $83.60 \pm 4.47$ \\
Acrylic/u- $Z \mathrm{rO}_{2}$ & $77.50 \pm 4.08$ \\
Acrylic/m- $-\mathrm{ZrO}_{2}-3$ & $135.71 \pm 9.05$ \\
Acrylic/m- $-\mathrm{ZrO}_{2}-5$ & $127.50 \pm 6.07$ \\
Acrylic/m- $-\mathrm{ZrO}_{2}-7$ & $125.71 \pm 7.38$ \\
Acrylic/m- $-\mathrm{ZrO}_{2}-10$ & $123.57 \pm 8.57$ \\
Acrylic/m- $-\mathrm{ZrO}_{2}-15$ & $112.50 \pm 6.62$ \\
\hline
\end{tabular}

TABle 4: Abrasion resistance of coating based on acrylic resin and different contents of $\mathrm{m}-\mathrm{ZrO}_{2}-3$ nanoparticles.

\begin{tabular}{lr}
\hline Coating & Abrasion resistance (L/mil) \\
\hline Acrylic/0.5 wt.\% m- $\mathrm{ZrO}_{2}-3$ & $116.67 \pm 8.97$ \\
Acrylic/1 wt.\% m- $\mathrm{ZrO}_{2}-3$ & $120.83 \pm 9.29$ \\
Acrylic/2 wt.\% m- $\mathrm{ZrO}_{2}-3$ & $135.71 \pm 9.05$ \\
Acrylic/5 wt.\% m-ZrO-3 & $120.69 \pm 7.79$ \\
\hline
\end{tabular}

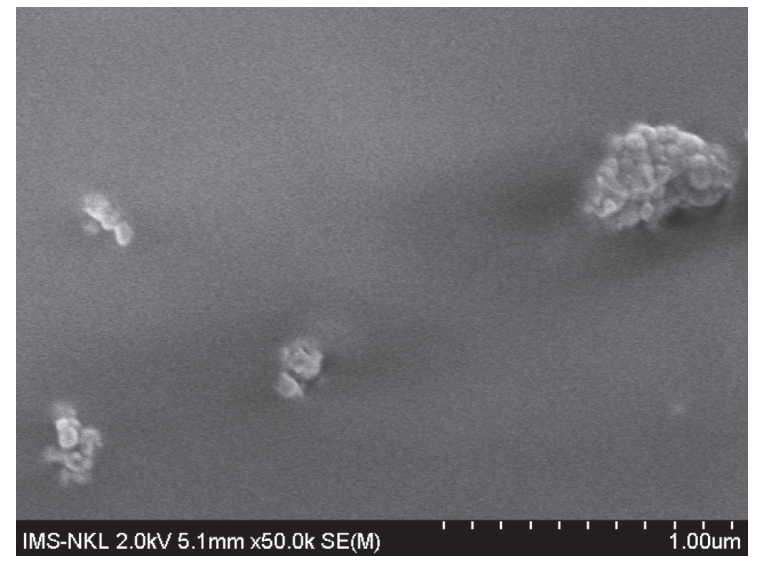

(a)

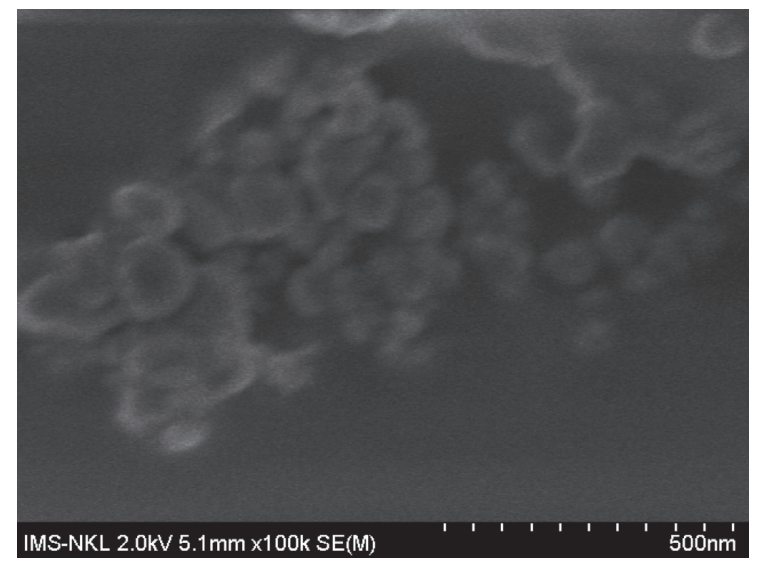

(b)

Figure 8: Continued. 


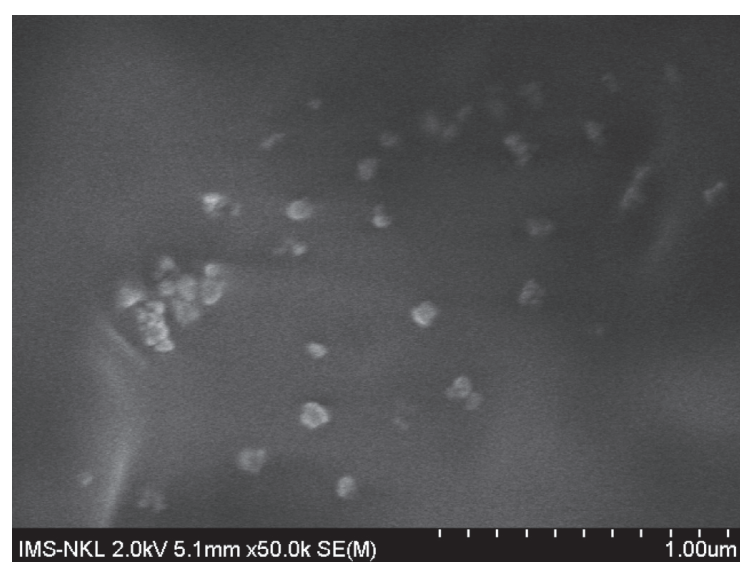

(c)

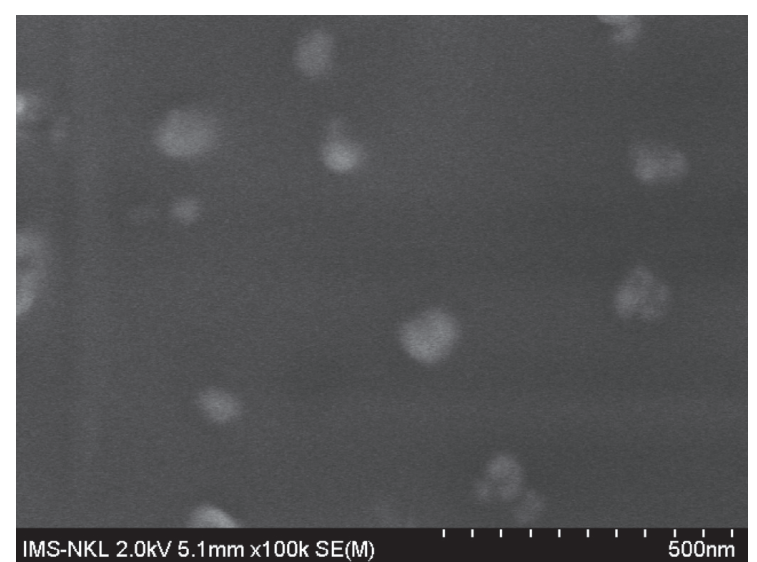

(d)

FIgURe 8: FESEM images of acrylic/2 wt.\% u- $\mathrm{ZrO}_{2}(\mathrm{a}, \mathrm{b})$ and acrylic/2 wt. $\% \mathrm{~m}-\mathrm{ZrO}_{2}-3$ (c, d) coatings.

3.5.2. Morphology. The FESEM images of the cross-surface of acrylic coating containing unmodified or modified $\mathrm{ZrO}_{2}$ nanoparticles are shown in Figure 8. It can be seen that the unmodified $\mathrm{ZrO}_{2}$ nanoparticles were agglomerated in acrylic resin matrix, while the $\mathrm{ZrO}_{2}$ nanoparticles modified with 3 wt.\% MSPMS were dispersed regularly in acrylic resin. The interaction of carbonyl and vinyl groups in MSPMS on the surface of modified $\mathrm{ZrO}_{2}$ nanoparticles with carbonyl groups in acrylic resin leading to the MSPMS plays a role of binder for acrylic resin and $\mathrm{ZrO}_{2}$ nanoparticles [29], resulting in the good dispersion of modified $\mathrm{ZrO}_{2}$ nanoparticles in acrylic resin. Thanks to the good dispersion of $\mathrm{m}-\mathrm{ZrO}_{2}-3$ nanoparticles in the acrylic resin, the abrasion resistance of the coating was improved as discussed above.

\section{Conclusions}

In conclusion, $\mathrm{ZrO}_{2}$ nanoparticles were modified successfully with 3-(trimethoxysilyl) propyl methacrylate silane (MSPMS). The modification process does not affect morphology and functional groups but cause the change in surface charge and thermal behavior of $\mathrm{ZrO}_{2}$ nanoparticles. The grafting efficiency of silane to $\mathrm{ZrO}_{2}$ nanoparticles reached 13.0\% when using 3 wt.\% MSPMS for modification. The content of organosilane and content of modified $\mathrm{ZrO}_{2}$ nanoparticles have an effect on the abrasion resistance of acrylic resin coating. The modified $\mathrm{ZrO}_{2}$ nanoparticles improved significantly the abrasion resistance of acrylic resin coating, especially, when using 2 wt.\% $\mathrm{ZrO}_{2}$ nanoparticles modified with $3 \mathrm{wt} \%$ MSPMS. This is the initial result to open up the prospects for the application of modified $\mathrm{ZrO}_{2}$ nanoparticles in coatings based on emulsion acrylic resin or other polymers.

\section{Data Availability}

The data used to support the findings of this study are included within the article.

\section{Conflicts of Interest}

The authors declare that they have no conflicts of interest.

\section{Acknowledgments}

This research was funded by the Vietnam National Foundation for Science and Technology Development (NAFOSTED) $(01 / 2020 / \mathrm{TN})$.

\section{References}

[1] S. K. Aysar, S. Elias, Z. Azmi, and S. Nayereh, "Structural and optical properties of zirconia nanoparticles by thermal treatment synthesis," Journal of Nanomaterials, vol. 2016, Article ID 1913609, 6 pages, 2016.

[2] Q. Mahmood, A. Afzal, H. M. Siddiqi, and A. Habib, "Sol-gel synthesis of tetragonal $\mathrm{ZrO}_{2}$ nanoparticles stabilized by crystallite size and oxygen vacancies," Journal of Sol-Gel Science and Technology, vol. 67, pp. 670-674, 2013.

[3] F. Sayılkan, M. Asiltürk, E. Burunkaya, and E. Arpaç, "Hydrothermal synthesis and characterization of nanocrystalline $\mathrm{ZrO}_{2}$ and surface modification with 2-acetoacetoxyethyl methacrylate," Journal of Sol-Gel Science and Technology, vol. 51, pp. 182-189, 2009.

[4] T. Sreethawong, S. Ngamsinlapasathian, and S. Yoshikawa, "Synthesis of crystalline mesoporous-assembled $\mathrm{ZrO}_{2}$ nanoparticles via a facile surfactant-aided Sol-Gel process and their photocatalytic dye degradation activity," Chemical Engineering Science, vol. 228, pp. 256-262, 2013.

[5] K. Xu, S. Zhou, and L. Wu, "Effect of highly dispersible zirconia nanoparticles on the properties of UV-curable poly (urethane-acrylate) coatings," Journal of Materials Science, vol. 44, pp. 1613-1621, 2009.

[6] K. Kan, D. Moritoh, Y. Matsumoto, K. Masuda, K. Kobiro, and M. Ohtani, "Nanoscale effect of zirconia filler surface on mechanical tensile strength of polymer composites," Nanoscale Research Letters, vol. 15, 51 pages, 2020.

[7] Y. Hu, G. Gu, S. Zhou, and L. Wu, "Preparation and properties of transparent $\mathrm{PMMA} / \mathrm{ZrO}_{2}$ nanocomposites 
using 2-hydroxyethyl methacrylate as a coupling agent," Polymer, vol. 52, pp. 122-129, 2011.

[8] M. M. Gad, S. M. Fouda, F. A. Al-Harbi, R. Näpänkangas, and A. Raustia, "PMMA denture base material enhancement: a review of fiber, filler, and nanofiller addition," International Journal of Nanomedicine, vol. 12, pp. 3801-3812, 2017.

[9] W. Yu, X. Wang, Q. Tang, M. Guo, and J. Zhao, "Reinforcement of denture base PMMA with $\mathrm{ZrO}_{2}$ nanotubes," Journal of the Mechanical Behavior of Biomedical Materials, vol. 32, pp. 192-197, 2014.

[10] F. M. Michael, M. R. Krishnan, A. Fathima, A. Busaleh, A. Almohsin, and E. H. Alsharaeh, "Zirconia/graphene nanocomposites effect on the enhancement of thermo-mechanical stability of polymer hydrogels," Mater Today Commun, vol. 21, Article ID 100701, 2019.

[11] K. Yamani, R. Berenguer, A. Benyoucef, and E. Morallon, "Preparation of polypyrrole (PPy)-derived polymer $/ \mathrm{ZrO}_{2}$ nanocomposites," J Therm Anal Calorim, vol. 135, pp. 20892100, 2019.

[12] H. Azizi and R. Eslami-Farsani, "Study of mechanical properties of basalt fibers/epoxy composites containing silane-modified nanozirconia," Journal of Industrial Textiles, vol. 19, Article ID 152808371988753, 2019.

[13] D. Toorchi, H. Khosravi, and E. Tohidlou, "Synergistic effect of nano- $\mathrm{ZrO}_{2} /$ graphene oxide hybrid system on the highvelocity impact behavior and interlaminar shear strength of basalt fiber/epoxy composite," Journal of Industrial Textiles, vol. 50, Article ID 152808371987992, 2019.

[14] H. Yan, R. Ning, G. Liang, Y. Huang, and T. Lu, "The effect of silane coupling agent on the sliding wear behavior of nanometer $\mathrm{ZrO}_{2}$ /bismaleimide composites," Journal of Materials Science, vol. 42, pp. 958-965, 2007.

[15] M. Skovgaard, K. Almdal, and A. van Lelieveld, "Stabilization of metastable tetragonal zirconia nanocrystallites by surface modification," Journal of Materials Science, vol. 46, no. 6, pp. 1824-1829, 2010.

[16] W. Guangyu, W. Shaoguo, Q. Suping, W. Jihu, W. Changrui, and C. Yabo, "Synthesis of novel nano hyperbranched polymer resin and its corrosion resistance in coatings," Progress in Organic Coatings, vol. 140, Article ID 105496, 2020.

[17] W. Tamaki, I. Kuniaki, and U. Tadashi, "Properties of organic-inorganic composite materials prepared from acrylic resin emulsions and colloidal silicas," Journal of Applied Polymer Science, vol. 101, no. 3, pp. 2051-2056, 2006.

[18] W. Zhang, L. Zhu, H. Ye, H. Liu, and W. Li, "Modifying a waterborne polyacrylate coating with a silica sol for enhancing anti-fogging performance," RSC Advances, vol. 6, no. 95, pp. 92252-92258, 2016.

[19] X. Wang, B. Pang, Q. Zhu, J. Yu, H. Dong, and L. Dong, "Electrical properties of acrylic resin composite thin films with graphene/silver nanowires," Journal of Applied Polymer Science, vol. 132, no. 32, 2015.

[20] D. Toorchi, E. Tohidlou, and H. Khosravi, "Enhanced flexural and tribological properties of basalt fiber-epoxy composite using nano-zirconia/graphene oxide hybrid system," Journal of Industrial Textiles, vol. 50, Article ID 152808372092057, 2020.

[21] P. Hui, W. XiaoDong, X. ShaSha, Y. LaiGui, and Z. ZhiJun, "Preparation and characterization of $\mathrm{TiO}_{2}$ nanoparticles surface-modified by octadecyltrimethoxysilane," Indian Journal of Engineering and Materials Sciences, vol. 20, pp. 561-567, 2013.
[22] J. Zhao, M. Milanova, M. M. C. G. Warmoeskerken, and V. Dutschk, "Surface modification of $\mathrm{TiO}_{2}$ nanoparticles with silane coupling agents," Colloids and Surfaces A: Physicochemical and Engineering Aspects, vol. 413, pp. 273-279, 2012.

[23] L. Peng, W. Qisui, L. Xi, and Z. Chaocan, "Investigation of the states of water and $\mathrm{OH}$ groups on the surface of silica," Colloids and Surfaces A: Physicochemical and Engineering Aspects, vol. 334, pp. 112-115, 2009.

[24] V. R. Chinchamalatpure, S. M. Chore, S. S. Patil, and G. N. Chaudhari, "Synthesis and electrical characterization of ZrO2 thin films on Si (100)," Journal of Modern Physics, vol. 3, no. 01, pp. 69-73, 2012.

[25] S. Sagadevan, J. Podder, and I. Das, "Hydrothermal synthesis of zirconium oxide nanoparticles and its characterization," Journal of Materials Science: Materials in Electronics, vol. 27, no. 6 , pp. 5622-5627, 2016.

[26] Y. Xia, C. Zhang, J. X. Wang, D. Wang, X. F. Zeng, and J. F. Chen, "Synthesis of transparent aqueous $\mathrm{ZrO}_{2}$ nanodispersion with a controllable crystalline phase without modification for a high-refractive-index nanocomposite film," Langmuir, vol. 34, no. 23, pp. 6806-6813, 2018.

[27] S. F. Chuang, L. L. Kang, Y. C. Liu et al., "Effects of silane- and MDP-based primers application orders on zirconia-resin adhesion -A ToF-SIMS study," Dental Materials, vol. 33, no. 8, pp. 923-933, 2017.

[28] M. Danaei, M. Dehghankhold, S. Ataei et al., "Impact of particle size and polydispersity index on the clinical applications of lipidic nanocarrier systems," Pharmaceutics, vol. 10, no. 2, p. 57, 2018.

[29] https://www.shinetsusilicone-global.com/catalog/pdf/Silane Coupling Agents_e.pdf. 